\title{
Small intestinal bacterial overgrowth syndrome in children
}

\author{
Katarzyna Siniewicz-Luzeńczyk ${ }^{1}$, Agnieszka Bik-Gawin ${ }^{1}$, Krzysztof Zeman¹, Leokadia Bąk-Romaniszyn ${ }^{2}$ \\ ${ }^{1}$ Department of Paediatrics, Immunology, and Nephrology, Polish Mother's Memorial Hospital Research Institute, Lodz, Poland \\ ${ }^{2}$ Department of Nutrition in Gastrointestinal Disease, Medical University of Lodz, Lodz, Poland
}

Prz Gastroenterol 2015; 10 (1): 28-32 DOI: $10.5114 /$ pg.2014.47494

Key words: small intestinal bacterial overgrowth syndrome, abdominal pain, hydrogen breath test, children. Address for correspondence: Katarzyna Siniewicz-Luzeńczyk MD, Department of Paediatrics, Immunology, and Nephrology, Polish Mother's
Memorial Hospital Research Institute, 281/289 Rzgowska St, 93-338 Lodz, Poland, phone: +48 422711381, fax: +48 422711380 , e-mail: siniewicz@wp.pl

\begin{abstract}
Introduction: Small intestinal bacterial overgrowth syndrome (SIBO) is defined as an increased number of nonpathogenic bacteria over $10^{5}$ organisms in 1 millilitre of small intestine content. The most common predisposing factors include, among others, gut motility disorders and chronic use of proton pump inhibitors. The results of recent studies indicate the importance of SIBO in gastrointestinal diseases.

Aim: To assess the prevalence of SIBO in children with abdominal pain.

Material and methods: One hundred children ( 59 girls and 41 boys) aged from 4 to 17 years (mean age: $10.47 \pm 3.73$ years), hospitalised due to abdominal pain, were enrolled in the study. Hydrogen breath test (HBT) with lactulose was established among all patients. Expired air was analysed using a Gastrolyzer (Bedfont).

Results: The HBT result was positive in 63 (63\%) children with abdominal pain; including 40 girls (67.8\%) and 23 boys (56.1\%). The test was positive in the group of $29(46 \%)$ children aged under 10 years and in the group of 34 (54\%) children aged over 10 years. Among the patients who reported for the control study $88 \%$ achieved a normalisation of HBT after treatment.

Conclusions: The prevalence of positive HBT results in the group of patients with abdominal pain is over $60 \%$. Small intestinal bacterial overgrowth syndrome should be considered as one of the causes of abdominal pain in children. The SIBO in children shows a good response to treatment.
\end{abstract}

\section{Introduction}

Small intestinal bacterial overgrowth syndrome (SIBO) is defined as an increased number of nonpathogenic bacteria over $10^{5}$ organisms in 1 millilitre of small intestine content [1-3]. The most common predisposing factors include gut motility disorders and chronic use of proton pump inhibitors [2, 4]. The SIBO is characterised by a large variety of clinical pictures $[5,6]$. Symptoms of SIBO are directly associated with bacterial metabolism, intestinal mucosa damage that leads to impaired absorption of fat, proteins, carbohydrates, and fat-soluble vitamins [7, 8]. The most common and therefore most commonly reported symptoms of SIBO include diarrhoea, abdominal pain, and flatulence. Cases of weight loss, symptoms of iron deficiency anaemia, vitamin D deficiency, hypocalcaemia, and even osteoporosis as a late complication of SIBO are described in the litera- ture $[9,10]$. The course of SIBO is also considered to be completely asymptomatic [6].

The standardisation of the methods used in the diagnosis of SIBO is still under discussion. Some authors believe that the only method of diagnosing SIBO, regarded as the "gold standard", is microbiological examination of the content sampled from the proximal part of the small intestine [11]. It is a direct method classified as an invasive one, as well as quite expensive [6, $8,11]$. In addition, there are still no established procedures regarding the use of samples and microbiological techniques. There is also the risk of contamination of the aspirate with the oral cavity flora, and in the case of absolute anaerobic bacterial overgrowth, obtaining false negative results [6]. Thus, commonly used tests in the diagnosis of SIBO, especially in the paediatric population, are indirect methods, which include hydrogen breath tests, inhalation tests with $\mathrm{C}^{14}$-labeled substanc- 
es (glycocholic acid or D-xylose) and para-aminobenzoic acid test using bacterial ability to deconjugate bile acids. These are mainly non-invasive tests that are easy to perform and cheap; however, like other methods they are characterised by some limitations [6, 7, 12-15].

The main objective of therapeutic intervention in SIBO is the treatment of the primary disease, while antibiotic therapy is intended to modify intestinal microflora [5, 16-18]. An important element is nutritional supplementation, especially vital and mineral deficiencies.

Abdominal pain, considered as the leading symptom in diseases of the gastrointestinal tract in children and adolescents, is one of the most common causes of diagnosing children in the hospital $[19,20]$. It is considered that in the course of SIBO, bacteria actively participate in the fermentation process of disaccharides and lead to an excess of formed gases, which is associated with the feeling of distension and the presence of $a b$ dominal pain [4]. Thus, in the present study a detailed analysis of patients hospitalised due to abdominal pain was performed.

\section{Aim}

The aim of the study was the assessment of SIBO prevalence in children with abdominal pain.

\section{Material and methods}

One hundred children (59 girls and 41 boys) aged from 4 to 17 years (mean age: $10.47 \pm 3.73$ years), hospitalised in the Department in the years 2009-2013, were enrolled in the study. In the studied group 45 children (45\%) were under 10 years of age and 55 (55\%) over 10 years of age. The main cause of admission to the hospital in all patients was abdominal pain, and 38 (38\%) patients also had accompanying symptoms; 14 (36.9\%) children presented with constipation, $11(28.9 \%)$ nausea and/or vomiting, 6 (15.8\%) diarrhoea, 4 (10.5\%) fetor ex ore, and 3 patients (7.9\%) presented weak or lack of weight gain. Moreover, in the studied group the place of residence in 71 (71\%) children (42 (59\%) girls and $29(41 \%)$ boys) was urban, and in 29 (29\%) children (17 (58.6\%) girls and 12 (41.4\%) boys) it was rural.

The study included those patients who, during the 8 weeks preceding hospitalisation, were not subjected to antibiotic treatment. Hydrogen breath test (HBT) with lactulose (administered per os) was performed among all children as an additional test. Expired air was analysed using Gastrolyzer by Bedfont (according to the manufacturer). Expired air sample was rated fasting, and then at intervals of $15 \mathrm{~min}$ in the first hour and at intervals of $30 \mathrm{~min}$ in the second hour of the test. The initial concentration of hydrogen greater than 20 ppm (parts per million), or at least a 20 ppm increase between the maximum reading and the fasting value in the first hour of the test, was considered as a positive result. On the basis of the performed diagnostic procedures (including confirmation or exclusion of SIBO), $11(11 \%)$ patients were additionally diagnosed with inflammation of the upper gastrointestinal tract, and $6(6 \%)$ patients with gastro-oesophageal reflux.

\section{Statistical analysis}

Qualitative variables are presented as percentages. Continuous variables are presented as mean values with standard deviation for variables with normal distribution or as median values with interquartile range (2575 percentiles) for variables without a normal distribution. Normal distribution was verified with Shapiro-Wilk test. Differences between groups for variables with normal distribution were analysed using the Student $t$ test for independent couples, and for variables not normally distributed the nonparametric U Mann-Withney test was used. Analysis of categorical variables was performed using Pearson's $\chi^{2}$ test. Statistical analysis was performed with the use of Statistica programme 10.0PL (StatSoft, Poland). In all cases statistically significant probability of $\alpha$ error $(p)$ was considered as less than 0.05 .

\section{Results}

The HBT result was positive among 63 (63\%) children, including 40 girls (67.8\%) and 23 boys (56.1\%) (Figure 1 ). Pearson's $\chi^{2}$ test showed no statistically significant differences in the incidence of SIBO in terms of gender $(p=0.23)$.

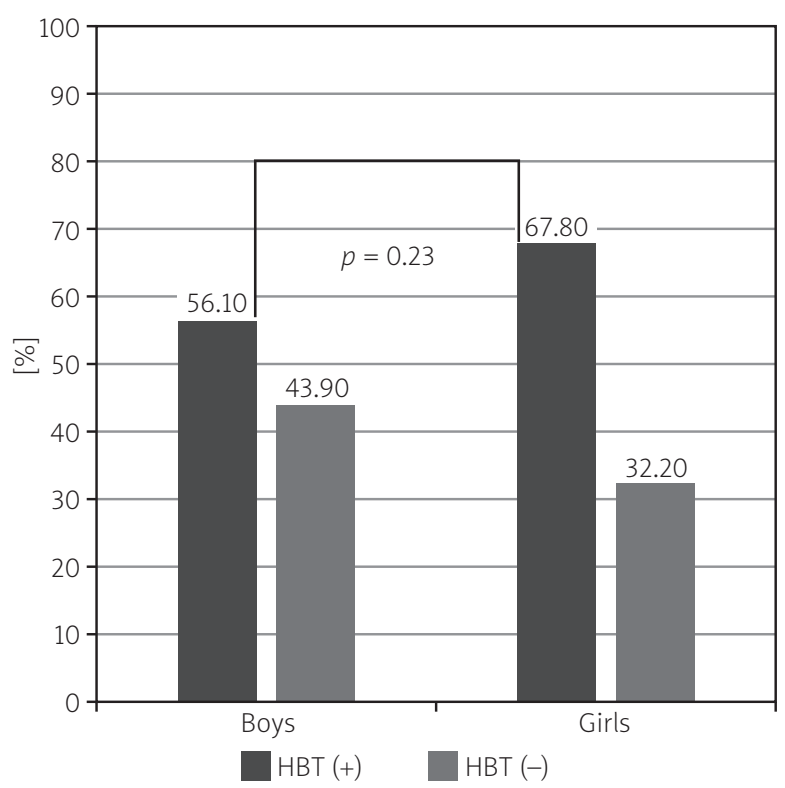

Figure 1. Prevalence of positive HBT result in children with abdominal pain $(n=100)$ 


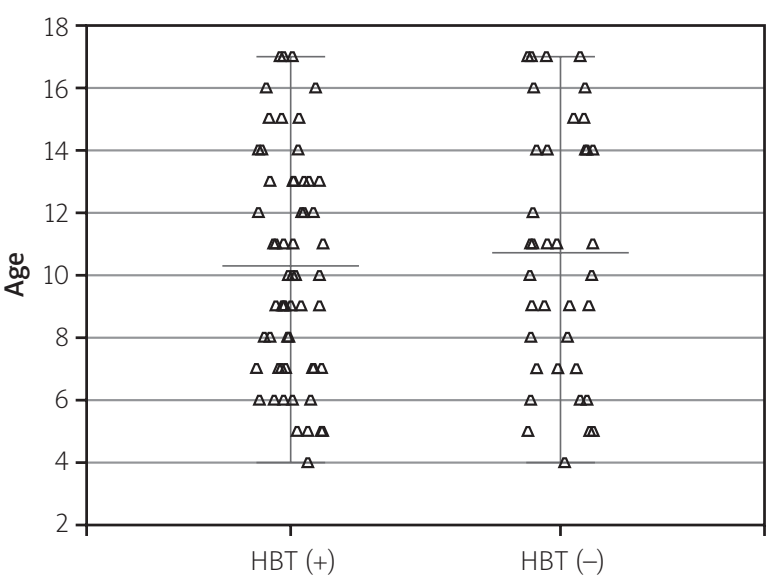

Figure 2. Age value distribution in the studied groups - patients with positive and negative HBT result

Furthermore, it was also demonstrated that the child's age did not predispose to the occurrence of SIBO $(p=0.65)$, as shown in Figure 2.

In the group of patients under 10 years of age, in 29 (46\%) children, including 15 (23.8\%) girls and $14(22.2 \%)$ boys, the result of the test indicated small intestinal bacterial overgrowth syndrome. A similar prevalence of SIBO was observed in patients over 10 years of age. The HBT result was positive in 34 (54\%) children, including 25 girls (39.7\%) and 9 boys (14.3\%). There was no difference in the incidence of SIBO in terms of gender in the group of younger children, up to 10 years of age. However, in the group of older children, over 10 years of age, we observed a trend towards a higher incidence of SIBO in girls ( $p=0.07, \chi^{2}$ test).

Among 63 patients with positive HBT result, SIBO was confirmed in 26 (41.3\%) patients with other accompanying symptoms next to abdominal pain, including 9 (14.3\%) children with constipation, 7 (11.1\%) with nausea and/or vomiting, 5 (7.9\%) with a history of diarrhoea, 4 (6.4\%) of all patients with fetor ex ore, and $1(1.6 \%)$ with weight deficiency (Figure 3$)$. The statistical analysis excluded the possibility that the presence of any of these symptoms was helpful in the diagnosis of SIBO ( $p=0.4, \chi^{2}$ test).

On the basis of the performed diagnostic procedures 11 (11\%) patients were additionally diagnosed with inflammation of the upper gastrointestinal tract. In this group, 5 (7.9\% of patients with positive HBT) children obtained a positive result of HBT. The $\mathrm{pH}$-metric study was suggestive of acid gastro-oesophageal reflux in 6 patients, among whom SIBO was confirmed in 3 cases ( $4.8 \%$ of patients with positive HBT result).

In addition, the correlation between the place of residence of children (city/village) and the positive HBT

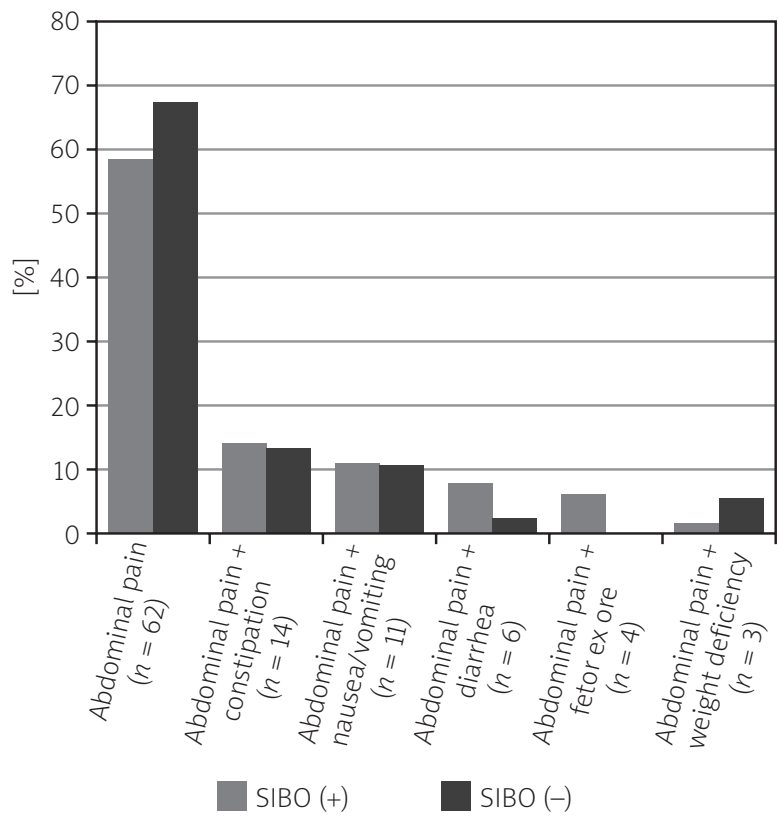

Figure 3. Prevalence of SIBO in patients with $a b-$ dominal pain and other accompanying gastrointestinal symptoms $(n=100 \%)$

result was assessed. The statistical analysis did not reveal significant differences in the prevalence of positive HBT between studied groups ( $p=0.9, \chi^{2}$ test).

All patients with positive HBT result, suggestive of SIBO, were treated with rifaximin, a derivative of rifamycine, absorbed from the gastrointestinal tract to a very small degree. All these patients were recommended for admission to the clinic after a period of 3 months for the control of HBT. Twenty-five (39.7\%) children, including 20 girls (50\%) and 5 boys (21.7\%) out of 63 diagnosed with SIBO, were reported for the designated control study. In this group of patients, 22 (88\%), including 17 (85\%) girls and 5 (100\%) boys, achieved a normal result of $\mathrm{HBT}$ and improvement or total withdrawal of abdominal pain. The HBT result was still positive, despite clinical improvement in 2 (10\%) girls, and in 1 (5\%) case $\mathrm{HBT}$ result was negative, while the girl still reported abdominal pain of comparable intensity and nature to that from the previous hospitalisation (Figure 4).

\section{Discussion}

There are a few reports in the literature on the prevalence of small intestinal bacterial overgrowth syndrome in children. The authors of most studies based the diagnosis of small intestinal bacterial overgrowth on results obtained using an indirect method: the hydrogen breath test with lactulose administered per os [6]. However, the results of the most commonly used diagnostic test differ from the results of the study 
considered as the gold standard, which is microbiological evaluation of the intestinal contents [21]. This test, although easy to perform and non-invasive, above all, is also characterised by numerous limitations. The objectivity of the results is affected by factors such as bacterial flora of the oral cavity and pharynx, antibiotic therapy, the use of laxatives, a diet rich in fibre for $24 \mathrm{~h}$ before the test, and motor activity of the gastrointestinal tract. Accelerated intestinal transit can generate false positive results of HBT and delayed gastric emptying false negative results $[3,6]$. It is worth emphasising that the definition of a positive HBT result, regardless of the substance, has not been clearly established [6].

The SIBO is characterised by a large variety of clinical pictures [22]. In the previous study, based on the analysis of chronic gastrointestinal symptoms, we showed that abdominal pain was the most common cause of admittance to hospital, as the only symptom among children (56\% of total) [23]. The HBT result in this group was suggestive of SIBO in up to $70 \%$ of patients, which is similar to the current results. In the present study we confirmed the presence of SIBO in $63 \%$ of children with abdominal pain, and the prevalence of SIBO was similar in the group of children below and above 10 years of age. Hutyra et al. demonstrated positive HBT results in $54.6 \%$ of children with symptoms of constipation-predominant irritable bowel syndrome, which was statistically different compared with patients with diarrhoea-predominant type [15]. Jarząb et al. in a study on the evaluation of upper gastrointestinal tract motility disorders in children, confirmed SIBO in more than $50 \%$ of patients [24]. Lisowska et al. demonstrated SIBO prevalence in $38.7 \%$ of children and adolescents with cystic fibrosis [25]. There are also studies conducted in adults in the literature, but it is difficult to objectively compare these results with the population of children and adolescents [26, 27].

Statistical analysis revealed that the place of child residence urban/rural did not correlate with positive result of HBT. The place of residence is also not mentioned as a potential risk factor for SIBO in the available literature.

All patients with positive HBT result, suggestive of SIBO, were treated with rifaximin at doses of $200 \mathrm{mg}$ to $400 \mathrm{mg}$ every $12 \mathrm{~h}$. In the present study, we showed that in 25 patients ( $39.7 \%$ with positive HBT) who reported for the control study, 22 (88\%) achieved a normal HBT result and significant clinical improvement. Recommendations for SIBO treatment include such antibiotics as: rifaximin, metronidazole, amoxicillin with clavulanic acid, clindamycin, ciprofloxacin, and trimethoprim with sulfamethoxazole $[8,28]$. According to some authors rifaximin may be an antibiotic of choice in the treatment

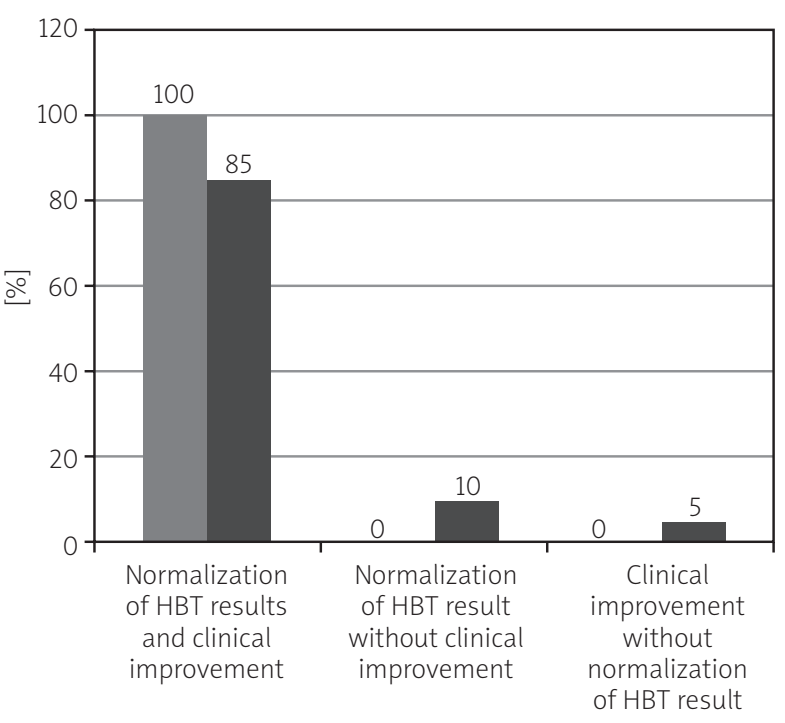

Figure 4. Assessment of relationship between positive or negative HBT result and symptoms in patients during 3 months after introduction of treatment $(n=25)$

of SIBO, as it is slightly absorbed from the gastrointestinal tract, has relatively few side effects, and compared with other antibiotics rarely exhibits the phenomenon of resistance [14]. No studies in the literature analysing improvement of HBT after eradication treatment in the paediatric population were found. Furnari et al. showed that $87 \%$ of patients treated with this antibiotic given per os, who achieved normalisation of HBT result, simultaneously revealed clinical improvement; however, a more effective treatment proved to be the application of rifaximin with partially hydrolysed guar gum [29].

\section{Conclusions}

Small intestinal bacterial overgrowth: occurs frequently, in more than $60 \%$ of patients with abdominal pain, should be considered as one of the causes of abdominal pain in children, shows a good response to treatment.

\section{Acknowledgments}

Work financed from own resources.

\section{Conflict of interest}

The authors declare no conflict of interest.

\section{References}

1. Singh VV, Toskes PP. Small bowel bacterial overgrowth: presentation, diagnosis, and treatment. Curr Gastroenterol Rep 2003; 5: 365-72.

2. Kirsch M. Bacterial overgrowth. Am J Gastroenterol 1990; 85: 231-7. 
3. Khoshini R, Dai SC, Lezcano S, et al. A systematic review of diagnostic tests for small intestinal bacterial overgrowth. Dig Dis Sci 2008; 53: 1443-54.

4. Saltzman JR, Russell RM. Nutritional consequences of intestinal bacterial overgrowth. Compr Ther 1994; 20: 523-30.

5. Shah SC, Day LW, Somsouk M, et al. Meta-analysis: antibiotic therapy for small intestinal bacterial overgrowth. Aliment Pharmacol Ther 2013; 38: 925-34.

6. Grace E, Shaw C, Whelan K, et al. Review article: small intes tinal bacterial overgrowth - prevalence, clinical features, current and developing diagnostic tests, and treatment. Aliment Pharmacol Ther 2013; 38: 674-88.

7. Mulak A, Kudyba M, Paradowski L. Intestinal dysbacteriosis during chronic proton pump inhibitor treatment [Polish]. Gastroenterol Pol 2012; 19: 166-70.

8. Hutyra T, Iwańczak B, Pytrus T, et al. Assessment of small intestinal bacterial overgrowth in functional disorders of alimentary canal in children. Adv Clin Exp Med 2009; 18: 493-500.

9. Klaus J, Spaniol U, Adler G, et al. Small intestinal bacterial overgrowth mimicking acute flare as pitfall in patients with Crohn's disease. BMC Gastroenterol 2009; 9: 61.

10. Stotzer PO, Johansson C, Mellstrom D, et al. Bone mineral density in patients with small intestinal bacterial overgrowth. Hepatogastroenterol 2003; 50: 1415-8.

11. Corazza GR, Menozzi MG, Strocchi A, et al. The diagnosis of small bowel bacterial overgrowth. Reliability of jejunal culture and inadequacy of breath hydrogen testing. Gastroenterol 1990; 98: 302-9.

12. Gasbarrini A, Corazza GR, Gasbarrini G, et al. Methodology and indications of $\mathrm{H} 2$-breath testing in gastrointestinal diseases: the Rome Consensus Conference. Aliment Pharmacol Ther 2009; 29: 1-49.

13. King CE, Toskes PP. Breath tests in the diagnosis of small intestinal bacterial overgrowth. Crit Rev Clin Lab Sci 1984; 21: 269-81.

14. Sachdev AH, Pimentel M. Gastrointestinal bacterial overgrowth: pathogenesis and clinical significance. Ther Adv Chronic Dis 2013; 4: 223-31.

15. Hutyra T, Iwańczak B. Small bowel bacterial overgrowth syndrome in children [Polish]. Pediatr Współcz Gastroenterol Hepatol Żywienie Dziecka 2010; 12: 130-4.

16. Gasbarrini A, Lauritano EC, Gabrielli M, et al. Small intestina bacterial overgrowth: diagnosis and treatment. Dig Dis 2007; 25: 237-40.

17. Attar A, Flourie B, Rambaud JC. Antibiotic efficacy in small intestinal bacterial overgrowth-related chronic diarrhea: a crossover, randomized trial. Gastroenterol 1999; 325: 1461-7.

18. Scarpellini E, Gabrielli M, Lauritano CE, et al. High dosage rifaximin for treatment of small intestinal bacterial overgrowth. Aliment Pharmacol Ther 2007; 7: 781-6.

19. Uścinowicz M, Kaczmarski M. Abdominal pain in children, clinical assessment using a pain scale [Polish]. Przegl Ped 2003; 33: 303-8.

20. Mielczarek J, Bąk-Romaniszyn L. Abdominal pain in children as a cause of admission to hospital - own observations [Polish] Przegl Ped 2010; 40: 213-7.

21. Gąsiorowska J, Czerwionka-Szaflarska M. Small intestinal bacterial overgrowth syndrome and irritable bowel syndrome [Polish]. Prz Gastroenterol 2013; 8: 165-71.
22. Fyderek K. Chosen diagnostical aspects in children with abdominal pain [Polish]. Przegl Lek 2007; 64: 46-7.

23. Siniewicz-Luzeńczyk K, Krakowska A, Ślemp A, et al. Small intestinal bacterial overgrowth in children with abdominal pain [Polish]. Pediatr Med Rodz 2012; 8: 120-3.

24. Jarząb A, Fyderek K, Pieczarkowski S. Myoelectrical activity of the stomach in children with irritable bowel syndrome [Polish]. Ped Współ Gastroenterol Hep Żyw Dziecka 2003; 4: 229-32.

25. Lisowska A, Popiel A, Cichy W, et al. The frequency of small intestinal bacterial overgrowth syndrome in cystic fibrosis patients - a pilot study. Pediatr Współcz Gastroenterol Hepatol Żywienie Dziecka 2009; 11: 19-22.

26. Madrid AM, Defilippi CC, Defilippi GC, et al. Small intestinal bacterial overgrowth in patients with functional gastrointestinal diseases. Rev Med Chil 2007; 135: 1245-52.

27. Pimentel M, Chow EJ, Lin HC. Normalization of lactulose breath testing correlates with symptom improvement in irritable bowel syndrome: a double-blind, randomized, placebo-controlled study. Am J Gastroenterol 2003; 98: 412-9.

28. Lauritano EC, Gabrielli M, Scarpellini E, et al. Antibiotic therapy in small intestinal bacterial overgrowth: rifaximin versus metronidazole treatment. Eur Rev Med Pharmacol Sci 2009; 13: 111-6.

29. Furnari M, Parodi A, Gemignani L, et al. Clinical trial: the combination of rifaximin with partially hydrolysed guar gum is more effective than rifaximin alone in eradicating small intestinal bacterial overgrowth. Alimet Pharmacol Ther 2010; 32: 1000-6

Received: 19.05 .2014

Accepted: 14.06.2014 